\section{Yield and Quality of Vitis Hybrid 'Suwannee' as Affected by Training System and Pruning Severity}

\author{
Peter C. Andersen ${ }^{1}$ and Charles A. Sims ${ }^{2}$ \\ Institute of Food and Agricultural Sciences, University of Florida, \\ Agricultural Research and Education Center, Monticello, FL 32344
}

Additional index words. bilateral cordon training system, bunch grape, cane training system

Abstract. The influence of bilateral cordon (BC) and cane training systems and level of pruning severity on vegetative and reproductive characteristics of Vitis hybrid 'Suwannee' were determined from 1987 to 1989. In 1987, yield and quality were similar on BC- and cane-trained vines. In 1988, shoot count, yield, and quality were similar regardless of training system and pruning severity $(50,70$, or 90 nodes per vine). When data from both training systems were combined, yield was related to the number of shoots. Vines pruned more severely compensated by producing more shoots from noncount (non-node) positions on the canes, cordon, or spurs. Similarly, in 1989 yield and berry quality were not affected by training system or levels of pruning severity (50, 70, 90, or 110 nodes), although berry weight was affected by training system, and shoot count and shoot length were affected by level of pruning severity. Interactive effects of training system and pruning level were not significant in either year. An analysis of combined data for $\mathbf{1 9 8 9}$ indicated that yield was affected by the number of nodes and shoots. Thus, 'Suwannee' may be trained to the BC system, which is more readily adapted to mechanization. Pruning to a specific number of nodes per vine was not critical.

A major limitation in the culture of bunch grape hybrids arises from a lack of quantitative data concerning training systems and levels of pruning severity. Vitis hybrids in Florida are trained to a cane system whereby four to eight canes are retained with $\approx 50$ to 110 nodes (depending on desired pruning severity) and are hand-tied to the wire(s). This system is labor-intensive and is not adaptable to mechanization. The bilateral cordon (BC) (Morris, 1985; Morris and Cawthon, 1980, 1981) or the Geneva double curtain (GDC) systems (Shaulis et al., 1973) are adaptable to mechanized pruning and harvesting, thereby greatly increasing vineyard management efficiency (Morris and Cawthon, 1981). Studies comparing yield and quality of several cultivars of $V$. labrusca (Morris, 1985; Morris and Cawthon, 1980, 1981; Morris et al., 1984a, 1985), French-American hybrids (Howell et al., 1987; Morris et al., 1984b; Wolpert et al., 1983), and V. vinifera (Ka-

Received for publication 29 Mar. 1990. Florida Agricultural Experiment Station Journal series no. R-00628. The cost of publishing this paper was defrayed in part by the payment of page charges. Under postal regulations, this paper therefore must be hereby marked advertisement solely to indicate this fact.

'Associate Professor. To whom reprint requests should be addressed.

${ }^{2}$ Assistant Professor, Dept. of Food Science and Human Nutrition, Univ. of Florida, Gainesville, FL 32611. simatis et al., 1985) have shown that the BC and cane-training systems resulted in similar yields and quality. Pruning severity (or the number of nodes) required for an optimum balance of yield and quality of $V$. labrusca 'Concord' and 'Niagra' has been determined (Morris and Cawthon, 1980, 1981; Morris et al., 1984a). Fundamental data are lacking concerning the influence of training systems and levels of pruning severity on bunch grape hybrids of the southernmost United States. A knowledge of the adaptability of these $\mathrm{Vi}$ tis hybrid cultivars to different training systems and the effect of node number on yield and quality are prerequisites for successful mechanization.

Our objective was to determine the influence of training system and pruning severity on vegetative and reproductive growth characteristics of Vitis hybrid 'Suwannee'.

A 0.23-ha experimental vineyard containing Vitis hybrid 'Suwannee' was established in 1985 at the Agricultural Research and Education Center, Monticello, Fla. In-row and between-row spacing were 2.4 and $3.0 \mathrm{~m}$, respectively. Vines were trained to a cane or a $\mathrm{BC}$ system at a height of $1.8 \mathrm{~m}$. All vines had a single trunk. Irrigation was supplied daily via drip irrigation.

The performance of BC- and cane-trained vines was evaluated from 1987 to 1989 . Vines were trained during 1985 to 1987 . BC-trained vines were established with cordons extending $1.2 \mathrm{~m}$ from either side of the trunk. Shoots emanating from all directions of the cordon were pruned to three-node spurs. For canetrained vines, two 1.0- to 1.4-m-long canes were selected on each side of the trunk and tied to the wire in 1987. Nodes were not counted for either training system during this initial year. Vines were hand-harvested $8 \mathrm{Aug}$. Cluster weight was determined from three intact, randomly selected bunches. The threebunch samples were frozen for quality analysis. For this analysis, fresh fruit samples $(\approx 500 \mathrm{~g})$ were crushed in plastic bags and squeezed through cheesecloth by hand. The juice was clarified by centrifugation at $3500 \times$ $\mathrm{g}$ for $15 \mathrm{~min}$. Soluble solids concentration (SSC) was measured with an. Abbé refractometer (Reichert Scientific Instruments, Buffalo, N. Y.) and $\mathrm{pH}$ was determined using a combination glass electrode. Titratable acidity was determined by diluting a 5-ml sample to $150 \mathrm{ml}$ with deionized water and titrating to $\mathrm{pH} 8.2$ with $0.1 \mathrm{~N} \mathrm{NaOH}$ (Zoecklein et al., 1990). Titratable acidity is expressed as percent tartaric acid equivalents. All analyses were performed in duplicate. The experiment was established and analyzed as a completely randomized design by analysis of variance procedures (SAS Institute, 1985). Each training system was replicated six times; each replicate consisted of three vines.

In 1988, the experimental design was expanded to encompass training system and levels of pruning severity. BC-trained vines were pruned to three- to five-node spurs for a total of 50, 70, or 90 nodes per vine. For cane-trained vines, three to eight canes, comprising 10 to 20 nodes, were selected per vine. Fifty, 70, or 90 nodes were retained for cane-trained vines. Total number of buds, which includes buds from count (nodes) and non-count positions on cordons, canes, and spurs, was determined on 29-31 Mar. Shoots were counted on 20-24 Apr. Vines were handharvested 8 Aug. Yield, cluster, and berry weights were measured and $\mathrm{pH}$, titratable acidity, and SSC were analyzed as described above. In addition, juice color was quantified from absorbance at $420 \mathrm{~nm}$ in a $10-\mathrm{mm}$ cell with a double-beam spectrophotometer (Zoecklein et al., 1990). The experiment was analyzed as a $2 \times 3$ factorial with a minimum of five single-vine replicates for each training system at each level of pruning severity. In addition, data were pooled for both training systems and subjected to regression analyses by the general linear model procedure (SAS Institute, 1985).

The training systems/pruning severity experiment of 1988 was repeated in 1989, with one modification: The number of nodes per vine was 50, 70, 90 (as in 1988), and 110. Vines with 110 nodes were selected from vines pruned to 90 nodes in 1988 . The number of buds from count (node) and non-count (other than node) positions were counted 1517 Mar. and 29-31 Mar., and shoot length and shoot number were measured 24-27 Apr. 
Table 1. Relationship between number of nodes, buds, and shoot production and yield for Vitis hybrid 'Suwannee' (1988). Data for bilateral cordon- and cane-trained vines were pooled.

\begin{tabular}{|c|c|c|c|c|c|}
\hline \multirow[b]{2}{*}{ Dependent variable ${ }^{z}$} & \multirow{2}{*}{$\begin{array}{c}\text { Independent variable } \\
\text { (no. retained) }\end{array}$} & \multirow[b]{2}{*}{ Equation } & \multicolumn{3}{|c|}{ Significance $^{y}$} \\
\hline & & & $r^{2}$ & Terms & Model \\
\hline Shoot production & $\begin{array}{l}\text { Node } \\
\text { Bud }\end{array}$ & $\begin{array}{l}y=82.17+0.336 x \\
y=69.96+0.367 x\end{array}$ & $\begin{array}{l}0.14 \\
0.21\end{array}$ & $\begin{array}{l}\mathrm{L}^{* *} \\
\mathrm{~L}^{* * *}\end{array}$ & $* *$ \\
\hline Yield & Shoot & $\mathrm{y}=176.7-5.00 \mathrm{x}+0.050 \mathrm{x}^{2}-0.0016 \mathrm{x}^{3}$ & 0.24 & $\mathrm{~L}^{*} \mathrm{Q}^{*} \mathrm{C}^{*}$ & $* *$ \\
\hline
\end{tabular}

${ }^{2}$ Only significant relationships are presented. Cluster and berry weights, $\mathrm{pH}$, titratable acidity, soluble solids concentration, and color were not significantly affected by the independent variables.

${ }^{y}$ Linear $(\mathrm{L})$, quadratic $(\mathrm{Q})$, and cubic $(\mathrm{C})$ components and overall model significant at $P=0.05\left({ }^{*}\right), 0.01\left({ }^{* *}\right)$, or $0.001\left({ }^{* * *}\right)$, based on $\mathrm{F}$ values.

Table 2. Effect of training system, level of pruning severity, and number of nodes retained on shoot production, shoot length, and berry weight of Vitis hybrid 'Suwannee' (1989).

\begin{tabular}{lcccc}
\hline \hline & $\begin{array}{c}\text { Nodes } \\
\text { retained } \\
\text { (no.) }\end{array}$ & \multicolumn{2}{c}{ Shoot production } & $\begin{array}{c}\text { Berry } \\
\text { wt } \\
\text { Training system }\end{array}$ \\
\cline { 3 - 5 } & 50 & No. & $\begin{array}{c}\text { Length } \\
(\mathrm{cm})\end{array}$ & $\begin{array}{c}\text { (g) } \\
\text { Cordon }\end{array}$ \\
& 70 & 89 & 101 & 3.1 \\
& 90 & 104 & 100 & 3.4 \\
& 110 & 104 & 104 & 3.3 \\
Canc & & 141 & 93 & 3.2 \\
& 50 & 81 & 89 & 3.1 \\
& 70 & 89 & 100 & 3.2 \\
& 90 & 111 & 108 & 2.8 \\
Training system & 110 & 119 & 86 & 3.0 \\
Node no. & & NS & NS & $*$ \\
\hline
\end{tabular}

${ }^{2}$ Only significant relationships are presented: yield, cluster weight, $\mathrm{pH}$, titratable acidity, soluble solids concentration, and color were not affected by training system or node number. All training system $x$ node number interactions were not significant.

Ns,*,***Nonsignificant or significant at $P=0.05$ or 0.001 , respectively.

The experiment was analyzed as a $2 \times 4$ factorial, with a minimum of five single-vine replicates for each treatment. Data were also pooled for both training systems, as in 1988, and analyzed by regression procedures (SAS Institute, 1985). Vines were hand-harvested 17 July. Berry weight was estimated from a 10-berry sample. Yield, cluster weight, $\mathrm{pH}$, titratable acidity, and SSC were determined as described previously.

Yield, cluster weight, $\mathrm{pH}$, titratable acidity, and SSC differed by no more than $5 \%$ to $10 \%$ for BC-trained and cane-trained vines during 1987 and none of the differences were significant (data not shown). In 1988, there were no significant main effects (training system or node number) or significant interactions (data not shown). Despite a rather wide range in level of pruning severity (50 to 90 ), the number of shoots per vine were similar (95 to 108). Remaining variables [yield (15.3-19.1 kg/vine), cluster weight (108-143 $\mathrm{g})$, berry weight (3.1-3.4 g), $\mathrm{pH}(3.50-3.59)$, titratable acidity $(0.81 \%$ to $0.88 \%)$, SSC (12.4-13.7), and color (abs at $420 \mathrm{~nm} \mathrm{0.308-}$ $0.362)]$ were also similar across treatments. $\mathrm{BC}$ - and cane-trained vines were analyzed collectively since dependent variables were not affected by training system. Few significant correlations occurred when the dependent variables were related to the independent variables, number of nodes, buds, and shoots (Table 1). Shoot count was weakly correlated with number of nodes $\left(r^{2}=0.14\right)$ and buds $\left(r^{2}=0.21\right)$, with a linear model. Yield was weakly correlated with number of shoots $\left(r^{2}=0.24\right)$, with a cubic model.

Shoot production was significantly affected by number of nodes in 1989 , yet a
$120 \%$ increase in the latter translated into only a $50 \%$ increase in the former (Table 2). The number of shoots produced increased $20 \%$ when the 50- and 90-node treatments were compared. The only other significant effect associated with number of nodes was shoot length. Yield was conspicuously low in 1989 (4.4 to $7.4 \mathrm{~kg} / \mathrm{vine}$ ), after high yields during 1988 for all treatments. A higher berry weight for the BC-trained vines was the only significant training-system effect. The range of values of other dependent variables were as follows: cluster weight (60-82 g), $\mathrm{pH}$ (3.25-3.47), titratable acidity (1.00-1.19), and SSC (12.5-14.7). No significant training system node interactions occurred for any variable.

Dependent variables were compared to the number of nodes, buds, and shoots for 1989 data (Table 3 ). Shoot production was positively correlated with number of nodes and buds. Conversely, shoot length was inversely correlated to these variables. Yield was weakly correlated with number of nodes and shoots.

Training system and levels of pruning severity had little or no influence on yield and quality of 'Suwannee' grapes. Cane pruning is considered to be among the most difficult and costly of all training systems (Winkler et al., 1974), although it is currently the recommended training system for Vitis hybrid bunch grapes in Florida (Cox, 1986). The BC-training system is adaptable to mechanical pruning and harvesting, and experiments on V. labrusca CV. Concord have shown that yield and quality are similar to cane-pruning systems (Morris and Cawthon, 1980, 1981; Morris et al., 1984a, 1985). The BC-training system is also currently used on many cultivars of $V$. vinifera in California (Kasimatis et al., 1985; Winkler et al., 1974). The major perceived impediment to a BC-trained system for Vitis hybrid bunch grapes in the southernmost United States is an accumulation of Xylella fastidiosa (the bacterium responsible for Pierce's disease) in the xylem vessels of the cordon (J. Mortensen, personal communciation). If this becomes a limitation of the BC-system, then cordon renewal may eventually become necessary.

Some of the lack of effect of number of nodes retained may be ascribed to a relatively weak correlation between this variable and shoot production (Tables 1 and 3). Data from both training systems indicate that, in 1988, shoot count varied from 95 to 108 for node counts of 50 to 90 . For the 50 -node treatment, $\approx 50 \%$ of the shoots were derived from primary buds of nodes; the remainder were derived mostly from latent primary buds on the cordon, spurs (or cane), and to a lesser extent from secondary buds. The lesser the pruning severity, the greater the proportion of primary shoots derived from nodes. Clearly, since yields of the two training systems were not significantly affected by level of pruning severity, shoots emanating from other areas of the vine were about as productive as primary shoots derived from nodes.

Similarly, the percentage of total yield derived from nodes (count positions) or noncount positions of French-American hybrid grapes varies with training system and level of pruning severity (Howell et al., 1987; Pool et al., 1978; Wolpert et al., 1983). Jackson et al. (1984) found that V. vinifera pruned less severely produced a lower number of shoots per node, although yield was sometimes increased with many nodes due to a higher number of clusters per shoot. In our study, when pruning levels ranged from 50 to 110 nodes per vine, the number of nodes and shoots were positively correlated (Table 2 ). Although for each training system an increase in shoot production did not translate into an increase in yield or change in quality of the fruit in either year, the combined data indicated that yield was weakly correlated to the number of shoots in 1988 (Table 1) and to the number of shoots and nodes in 1989 (Table 3).

In conclusion, 'Suwannee' grape appears to be amenable to a BC-training system without sustaining a reduction in yield or quality. Pruning to a specific number of nodes did not translate to a proportional number of shoots. Fruitfulness appeared to be largely self-regulating, in that great variations in level 
Table 3. Relationship between number of nodes, buds, shoot production, and yield for Vitis hybrid 'Suwannee' (1989). Data for bilateral cordon- and cane-trained vines were pooled.

\begin{tabular}{|c|c|c|c|c|c|}
\hline \multirow{2}{*}{$\begin{array}{c}\text { Dependent } \\
\text { variable }^{z}\end{array}$} & \multirow{2}{*}{$\begin{array}{l}\text { Independent variable } \\
\text { (no. retained) }\end{array}$} & \multirow[b]{2}{*}{ Equation } & \multirow[b]{2}{*}{$r^{2}$} & \multicolumn{2}{|c|}{ Significance ${ }^{y}$} \\
\hline & & & & Term & Model \\
\hline \multirow[t]{2}{*}{ Shoot production } & Node & $y=49.38+0.703 x$ & 0.63 & $L^{* *}$ & $* * *$ \\
\hline & Bud & $y=34.67+0.64 x$ & 0.83 & $\mathrm{~L}^{* * *}$ & *** \\
\hline \multirow[t]{3}{*}{ Shoot length } & Node & $y=-25.4+2.02 x-0.013 x^{2}$ & 0.19 & $\mathrm{~L}^{* *} \mathrm{Q}^{* *}$ & $* *$ \\
\hline & Bud & $y=69.59+3.86 x-0.0268 x^{2}+0.000055 x^{3}$ & 0.35 & NS & ** \\
\hline & Shoot & $y=-15.46+2.16 x-0.0100 x^{2}$ & 0.20 & $\mathrm{~L}^{* *} \mathrm{Q}^{* *}$ & $* *$ \\
\hline \multirow[t]{2}{*}{ Yield } & Node & $y=2.77+0.0324 x$ & 0.14 & $L^{*}$ & * \\
\hline & Shoot & $\mathrm{y}=0.382+0.048 \mathrm{x}$ & 0.24 & $\mathrm{~L}^{* * *}$ & $* * *$ \\
\hline
\end{tabular}

${ }^{2}$ Only significant relationships arc presented. Cluster and berry weights, $\mathrm{pH}$, titratable acidity, soluble solids concentration, and color were not significantly affected by the independent variables.

y Linear (L), quadratic $(\mathrm{Q})$, and cubic $(\mathrm{C})$ components and overall model significant at $P=0.05\left({ }^{*}\right), 0.01\left({ }^{* *}\right)$, or $0.001\left({ }^{* * *}\right)$, based on $\mathrm{F}$ values.

of pruning severity had little or no influence on yield or quality. Pruning Vitis hybrid 'Suwannee' to a specific number of nodes was not a sufficiently precise method to manipulate crop load. Cluster thinning may be a reasonable alternative to regulate yield and quality, as in many cultivars of FrenchAmerican hybrid grapes (Howell et al., 1987; Pool et al., 1978; Wolpert et al., 1983). It is not clear whether the performance of other Vitis hybrids, such as 'Stover' or 'Blanc DuBois', is similar to that of 'Suwannee'; thus, one must avoid treating Vitis hybrid cultivars adapted to the southernmost United States collectively until provided with the quantitative data.

\section{Literature Cited}

Cox, W. 1986. Chemigation, trellising and machine harvesting of wine grapes, p. 141-145. In: M.C. Halbrooks (ed.). Proc. First Greater Grapes Symp., Univ. Florida, Gainesville.

Howell, G.S., T.K. Mansfield, and J.A. Wolpert. 1987. Influence of training system, pruning severity, and thinning on yield, vine size, and fruit quality of Vidal blanc grapevines. Amer. J. Enol. Vitic. 38:105-112.

Jackson, D.I., G.F. Steans, and P.C. Hemmings. 1984. Vine response to increased node number. Amer. J. Enol. Vitic. 35:161-163.

Kasimatis, A.N., K.W. Bowers, and E.P. Vilas. 1985. Conversion of cane-pruned Cabernet sauvignon vines to bilateral cordon training and a comparison of cane and spur pruning. Amer. J. Enol. Vitic. 36:240-244.

Morris, J.R. 1985. Approaches to more efficient vineyard management. HortScience 20:1008$\begin{array}{lllll}1 & 0 & 1 & 3\end{array}$.

Morris, J.R. and D.L. Cawthon. 1980. Mechanical trimming and node adjustment of cordontrained 'Concord' grapevines. J. Amer. Soc. Hort. Sci. 105:310-313.

Morris, J.R. and D.L. Cawthon. 1981. Yield and quality response of 'Concord' grapes (Vitis labrusca L.) to mechanized vine pruning. J. Amer. Soc. Vitic. Enol. 32:280-282.

Morris, J.R., D.L. Cawthon, and C.A. Sims. 1984a. Long-term effects of pruning severity, nodes per bearing unit, training system and shoot positioning on yield and quality of 'Concord' grapes. J. Amer. Soc. Hort. Sci. 109:676-683.

Morris, J.A., C.A. Sims, J.E. Bourque, and J.L. Oakes. 1984b. Influence of training system, pruning severity and spur length on yield and quality of six French-American hybrid grape cultivars. Amer. J. Enol. Vitic. 35:23-27.

Morris, J.A., C.A. Sims, and D.L. Cawthon. 1985. Yield and quality of 'Niagara' grapes as affected by pruning severity, nodes per bearing unit, training system and shoot positioning. J. Amer. Soc. Hort. Sci. 110:186-191.

Pool, R.M., C. Pratt, and H.D. Hubbard. 1978. Structure of base buds in relation to yield of grapes. Amer. J. Enol. Vitic. 29:3641.

SAS Institute. 1985. SAS/STAT guide for personal computers version 6th edition. SAS Institute, Inc., Cary, N.C.

Shaulis, N.J., J. Pollock, D. Crowe, and E.S. Shepardson. 1973. Mechanical pruning of grapevines: Progress 1968-1972. Proc. N.Y. State Hort. Soc. 118:61-69.
Winkler, A.J., J.A. Cook, W.M. Kliewer, and L.A. Lider. 1974. General viticulture. Univ. California Press, Berkeley.

Wolpert, J.A., G.S. Howell, and T.K. Mansfield. 1983. Sampling Vidal blanc grapes I. Effect of training system, pruning severity, shoot exposure, shoot origin, and cluster thinning on cluster weight and fruit quality. Amer. J. Enol. Vitic. 34:72-76.

Zoecklein, B.W., K.C. Fugelsang, B.H. Gump, and F.S. Nury. 1990. Production wine analysis. Van Nostrand Reinhold, New York. 